Emerging Materials Research

Volume 4 Issue EMR2

The microstructure, tensile response and fracture behavior of a high-performance structural steel: influence of orientation Gowda, Hotz, Patnaik, Manigandan and Srivatsan
Pages 255-264 http://dx.doi.org/10.1680/jemmr.15.00018 Research Article

Received 25/02/2015 Accepted 14/09/2015

Published online 16/09/2015

Keywords: alloys/mechanical properties/scanning electron microscopy

\title{
The microstructure, tensile response and fracture behavior of a high-performance structural steel: influence of orientation
}

\section{Sunil Gowda MS*}

Graduate student, Department of Civil Engineering, The University of Akron, Akron, Ohio, USA

\section{Carl Hotz MS}

Graduate student, Department of Civil Engineering, The University of Akron, Akron, Ohio, USA

\section{Anil Patnaik PhD}

Professor, Department of Civil Engineering, The University of Akron, Akron, Ohio, USA

\author{
Kannan Manigandan PhD \\ Research Scholar, Department of Mechanical Engineering, The University \\ of Akron, Akron, Ohio, USA
}

Tirumalai S. Srivatsan PhD

Professor, Department of Mechanical Engineering, The University of Akron, Akron, Ohio, USA

In this paper, the microstructure, hardness, tensile deformation and fracture behavior of a structural steel (ASTM A572-Grade 50) is presented and discussed. Specifically, the influence of test specimen orientation on microstructure of the as-provided material and resultant influence of microstructure on hardness, tensile properties and final fracture behavior are examined. Aspects related to the macroscopic mode and the governing intrinsic microscopic features that result from fracture of the steel specimens machined from the two orientations, longitudinal and transverse, are also examined. The microscopic mechanisms governing quasi-static deformation and final fracture behavior of this structural steel are discussed in light of the conjoint influence of test specimen orientation, intrinsic microstructural effects and nature of loading.

\section{Introduction}

In the time period spanning the last three decades, that is, since the onset of the 1980s, few to several manufacturers and producers of a spectrum of steels spanning the domains of carbon steel, mild steel, stainless steel, alloy steels, tool steels and even specialty steels have made a dedicated attempt to successfully engineer the selection and use of these steels for a wide variety of applications spanning the domains of both performance critical and nonperformance critical. This concurrently provided them with not only an incentive but also the much needed and required impetus to gradually shift their attention and action towards engineering the production, processing and use of high-strength steels for a wide range of commercial applications. The high-strength steels are particularly noted for offering an attractive combination of high tensile strength, acceptable to good fracture toughness and improved weldability coupled with better performance in environments spanning a range of aggressiveness, to include both aqueous and gaseous, when compared one-on-one with the mild steel counterpart. ${ }^{1-10}$ The production and processing, to include both primary and secondary, of the family of highstrength steels have culminated from noticeable advances in both the processing and manufacturing techniques currently in use in the steel industry, especially in the domain of thermomechanical processing. In particular, a careful control of heating and subsequent mechanical deformation processes during production of the steel can result in the formation of a fine grain size end product.

A noticeable advantage that results from selecting and using highstrength steel for an end application is that overall weight of the component can be drastically reduced, thereby making it possible, in many ways, to achieve: $(a)$ a reduction in the overall cost of fabrication, (b) a reduction in the cost of transportation of both the component and structure and $(c)$ concurrently enable ease in handling of both the material and the resultant component or structure. In the prevailing era, lightweight and thin elements are both desirable and essentially required for purpose of architecture and the creative design of aesthetic members and structures. A noticeable reduction in size of the end product means less consumption of the chosen steel during manufacturing. The high-strength steels of continuing interest to the civil construction industry are particularly noted for their high yield stress, while few of them are noted for their ability to offer marginal to acceptable ductility quantified by reduction in test specimen cross-sectional area. 
The development, emergence and sustained interest in the use of structural steel led to the initiation of its use in the civil construction industry. Due to its high strength and relatively low weight, structural steels find use for a spectrum of applications to include bridge construction, use as trusses and even for the construction of transmission towers. ${ }^{11-14}$ However, with the gradual evolution of time, an important, yet practical, application for structural steel was in the ship-building industry. Standard American Institute of Steel Construction ${ }^{15}$ shapes, such as wide-flange sections, angles and channels, are currently being used in building applications. Similar sections are also being used to build stiffened panels, which constitute ship bulk heads and hull girders. The stiffened panels are generally subject to the combined action of transverse thrust and lateral pressure. Sustained research studies driven by the need to understand the mechanical behavior of these steels have culminated in sufficient information being made available on the structural behavior of these stiffened panels under a spectrum of loading conditions. ${ }^{14}$

Selection of the appropriate steel for a specific application has an influence on the overall safety, reliability and even service life of a structure. ${ }^{7,8,13}$ Appropriate selection and use of a high-strength steel for the purpose of both engineering and developing a newer product necessitate the need for careful consideration to be given to all pertinent limit states, design procedures, fabrication practices and construction procedures followed coupled with a careful evaluation of all potential applications and the resultant end-users so as to help ensure both a safe and a reliable operation., ${ }^{7,811,16}$

The properties of a high-strength steel chosen for specific use in structural applications are often governed by the conjoint and mutually interactive influences of chemical composition, processing history (to include both primary processing and secondary processing), intrinsic microstructural features, temperature of operation, nature of loading and the presence of potential constraints due to both design and construction. ${ }^{16-21}$ Factors ranging from an increase in part thickness, incorporation of sharp changes in cross section or notches and an increase in loading rate coupled with lowering of the operating temperature can be detrimental to ductility, toughness and even overall fracture behavior of the chosen structural steel. ${ }^{19-21}$

In this paper, we present and discuss the influence of microstructure on tensile response and fracture behavior of a structural steel that has grown in stature to be chosen for use in applications spanning the domains of both performance critical and non-performance critical. A rationalization of the fracture behavior is made in light of the chemical composition, intrinsic microstructural effects, nature of loading and deformation characteristics of the microconstituents.

\section{Material}

The high-strength low-alloy steel chosen for this research study was ASTM A572. In recent years, its preferential selection for use in a variety of structural applications has earned for itself the name of 'structural steel'. The chemical composition of this steel is summarized in Table 1. Due to noticeable amounts of carbon and manganese, this steel is often referred to as 'high-carbon, low-alloy content' steel. This steel derives its strength from the formation, presence and dispersion of fine carbide particles through the microstructure.

Presence of carbon basically provides solid solution strengthening while concurrently enabling in a noticeable increase in hardenability arising from the formation, presence and dispersion of alloy carbide particles through the microstructure. The presence of manganese assists in the formation of carbides, which contribute, either directly or indirectly, to increase strength while concurrently resisting softening during heat treatment. To a limited extent, manganese also aids in refining the grain size resulting in a much desired fine grain size end product.

\section{Experimental procedures}

\subsection{Characterization of initial microstructure}

Samples of this high-carbon content steel were prepared for observation very much in conformance with standard procedures used for metallographic preparation of metal samples. This essentially involves coarse polish using progressively finer grades of silicon carbide ( $\mathrm{SiC}$ )-impregnated paper (i.e., 320 grit, 400 grit and 600 grit) followed by fine polishing using 5- and 1- $\mu \mathrm{m}$ alumina-based polishing compound suspended in distilled water as the lubricant. The as-polished samples were etched using nital reagent, that is, a solution mixture of nitric acid in ethanol. Etching helps reveal the following: (a) the grain boundaries, $(b)$ size of the grain, (c) morphology of the grain and $(d)$ other intrinsic features, such as the nature, morphology and distribution of the second-phase carbide particles through the microstructure of this high-carbon content steel. A light optical microscope was used to examine the polished and etched surfaces of the sample at low magnifications and subsequently photographed using bright-field illumination technique.

\subsection{Hardness testing}

\subsubsection{Microhardness test}

A basic mechanical property of a material is its hardness. The hardness test is an important and widely used test for the purpose of quickly evaluating the mechanical properties of monolithic metals, their alloy counterparts and even composite materials based on metal matrices. A simple yet appropriate definition

\begin{tabular}{lcccc} 
Material & $\mathbf{C}$ & Mn & P & S \\
A572 & 0.25 & 1.35 & 0.04 & 0.05 \\
\hline
\end{tabular}

Table 1. Chemical composition of A572 steel (in percentage weight) 
Emerging Materials Research

Volume 4 Issue EMR2
The microstructure, tensile response and fracture behavior of a high-performance structural steel: influence of orientation Gowda, Hotz, Patnaik, Manigandan and Srivatsan

\begin{tabular}{|c|c|c|c|c|c|c|c|}
\hline Orientation & & Trail 1 & Trail 2 & Trail 3 & Trail 4 & Trail 5 & Average hardness: $\mathrm{kg} / \mathrm{mm}^{2}$ \\
\hline \multirow[t]{3}{*}{ Longitudinal } & $\mathrm{D} 1: \mu \mathrm{m}$ & $83 \cdot 54$ & $86 \cdot 85$ & $86 \cdot 57$ & $82 \cdot 57$ & $91 \cdot 4$ & \\
\hline & $\mathrm{D} 2: \mu \mathrm{m}$ & $84 \cdot 56$ & 88.46 & $88 \cdot 64$ & $85 \cdot 1$ & $78 \cdot 2$ & \\
\hline & $H_{\mathrm{v}}: \mathrm{kg} / \mathrm{mm}^{2}$ & 263 & 241 & 242 & 264 & 238 & 250 \\
\hline \multirow[t]{3}{*}{ Transverse } & $\mathrm{D} 1: \mu \mathrm{m}$ & $85 \cdot 56$ & $82 \cdot 8$ & $91 \cdot 49$ & 84.96 & $80 \cdot 87$ & \\
\hline & $\mathrm{D} 2: \mu \mathrm{m}$ & $87 \cdot 54$ & $92 \cdot 18$ & 88.41 & 87.03 & $83 \cdot 11$ & \\
\hline & $H_{\mathrm{v}}: \mathrm{kg} / \mathrm{mm}^{2}$ & 248 & 242 & 229 & 251 & 275 & 249 \\
\hline
\end{tabular}

Table 2. Microhardness measurements on structural steel A572 steel
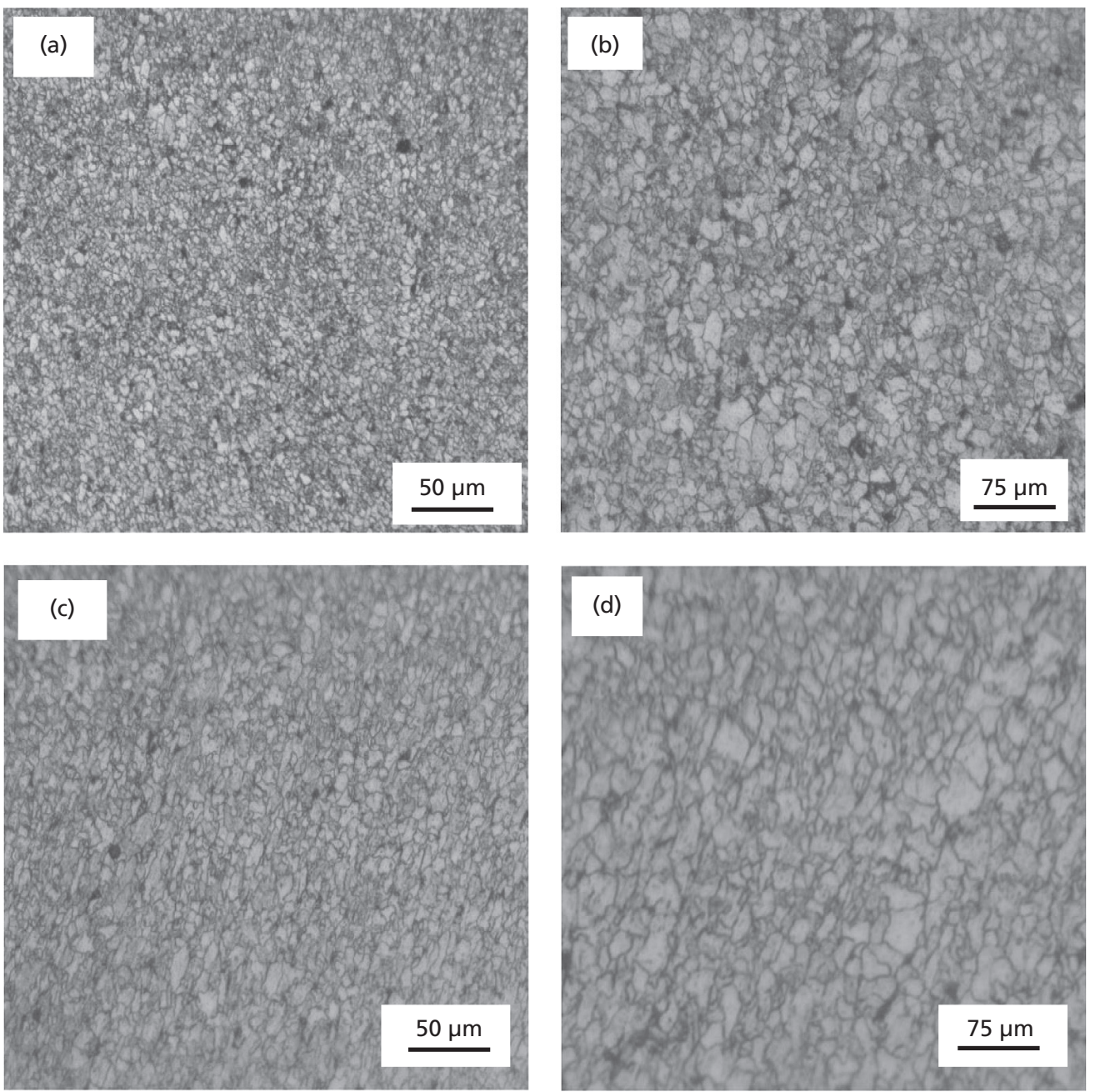

Figure 1. Optical micrographs showing microstructure of structural steel A572 at two different magnifications of (a) longitudinal at 100x, (b) longitudinal at 200x, (c) transverse at 100x, (d) transverse at 200x

that has been recorded for hardness is the resistance offered by the material to indentation, that is, permanent deformation and cracking. ${ }^{20,21}$ A direct measurement of hardness is both a simple and useful technique for characterizing the baseline mechanical properties while concurrently investigating, establishing and rationalizing the role and contribution of intrinsic microstructural constituents. Overall, the hardness test can be safely considered to be both simple and easy enough to enable it to be safely categorized 
Emerging Materials Research

Volume 4 Issue EMR2
The microstructure, tensile response and fracture behavior of a high-performance structural steel: influence of orientation Gowda, Hotz, Patnaik, Manigandan and Srivatsan

\begin{tabular}{lcc} 
& \multicolumn{2}{c}{$\begin{array}{c}\text { Macrohardness } \\
\text { (longitudinal) }\end{array}$} \\
\cline { 2 - 3 } Orientation & HR $_{\mathrm{B}}$ & $\mathrm{MPa}$ \\
Longitudinal & 84 & 437 \\
& 85 & 448 \\
& 86 & 455 \\
Transverse & 80 & 406 \\
& 81 & 413 \\
& 82 & 424 \\
& 84 & 444 \\
& 81 & 413 \\
& 83 & 437 \\
& 85 & 448 \\
\hline
\end{tabular}

Table 3. Macrohardness measurements made on structural steel A572

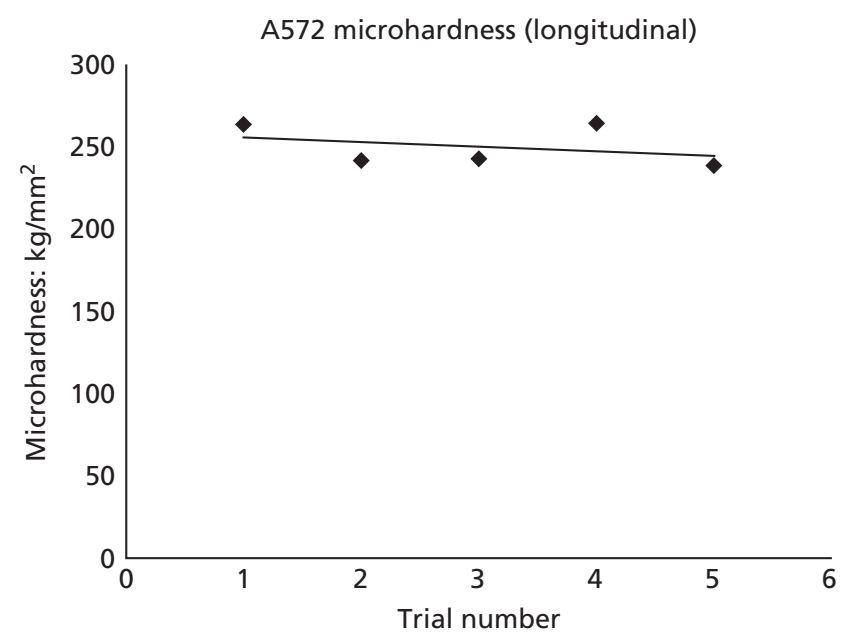

Figure 2. A profile showing the variation of microhardness $\left(\mathrm{kg} / \mathrm{mm}^{2}\right)$ taken across the length of the mounted sample of A572

as being non-destructive $e^{7,9,21,22}$. In this study, the Vickers microhardness $\left(H_{\mathrm{v}}\right)$ measurements were made on a microhardness tester using an indentation load of $200 \mathrm{~g}$ and a dwell time of $15 \mathrm{~s}$, with the aid of a Vickers tool indenter (Model: INSTRON Wilson Tukon 2100). The indenter (made of diamond) has a square-based pyramidal geometry with an included angle of $136^{\circ}$. The indenter rests for a specified length of time on the polished surface of the test specimen. The machine makes an indent, or impression, on the polished surface of the sample whose diagonal size was measured using a low magnification optical microscope. The area of the impression is directly proportional to the load used and a load independent hardness number can be found. The $H_{\mathrm{v}}$ number is the ratio of applied load to the surface area of the indent and was

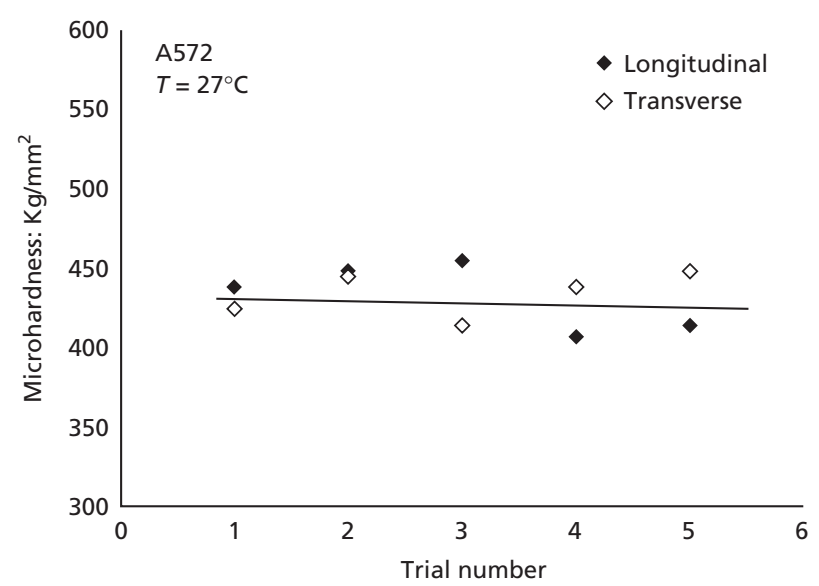

Figure 3. A profile showing the variation of macrohardness $\left(\mathrm{kg} / \mathrm{mm}^{2}\right)$ taken across the length of the mounted sample of A572

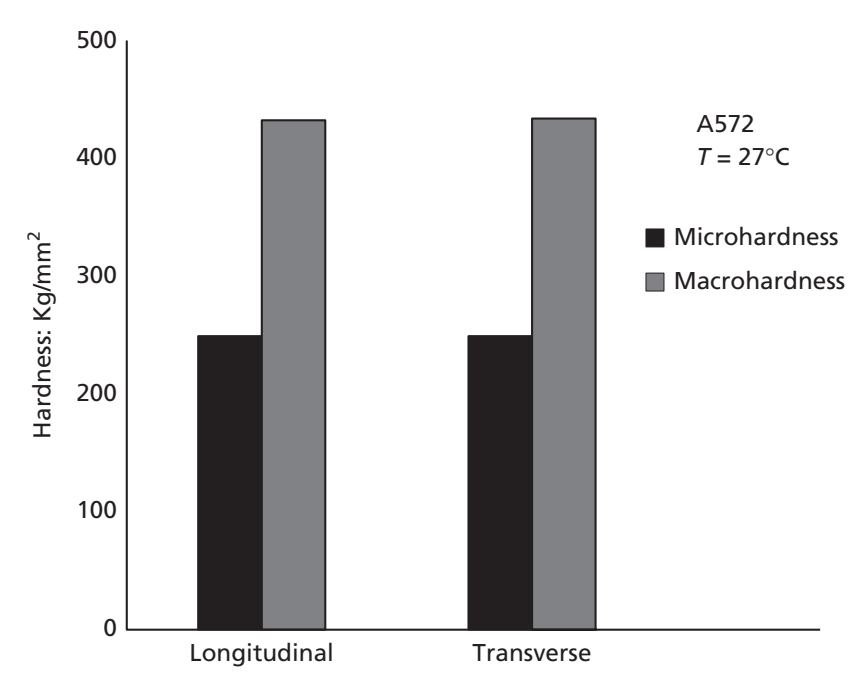

Figure 4. Bar graph comparing the macrohardness and microhardness of A572 steel in the two orientations: longitudinal and transverse

provided by the test machine. Five indents were made edge-toedge across the polished surface along both the longitudinal and transverse directions of the chosen high-carbon, low-alloy content steel A572 sample. The result is reported as the average value in units of $\mathrm{kg} / \mathrm{mm}^{2}$. The indentation load used was $500 \mathrm{~g}(4.9 \mathrm{~N})$ for a dwell time of $10 \mathrm{~s}$. The hardness number was computed using the expression:

$$
\text { 1. } \quad H_{\mathrm{v}}=1.8545\left[P / d^{2}\right]
$$

where $P$ is the indentation load used and $d$ is the average length of the two diagonals in millimeter. The microhardness measurements (trials and average) made on the structural steel samples (longitudinal and transverse) are provided in Table 2. 
Emerging Materials Research

Volume 4 Issue EMR2
The microstructure, tensile response and fracture behavior of a high-performance structural steel: influence of orientation Gowda, Hotz, Patnaik, Manigandan and Srivatsan

\subsection{Mechanical testing}

Cylindrical test specimens, conforming to specifications outlined in ASTM, ${ }^{23}$ were precision machined from the chosen steel. The threaded test specimens measured $59 \mathrm{~mm}$ in length and $6.35 \mathrm{~mm}$ in diameter at the thread section. The gage section of the machined test specimen measured $12.5 \mathrm{~mm}$ in length and $3.175 \mathrm{~mm}$ in diameter. To minimize the effects of surface irregularities and finish, the gage sections of the machined test specimens were mechanically ground using progressively finer grades of SiC-impregnated emery paper. The purpose of polishing was to remove any and all circumferential scratches and surface machining marks.

Uniaxial tensile tests were performed until failure on a fully automated, closed-loop servohydraulic mechanical test machine (INSTRON Model 8500 plus) equipped with a $100 \mathrm{KN}$ load cell. The test specimens were deformed at a constant strain rate of $0 \cdot 0001 / \mathrm{s}$. An axial 12.5-mm gage length extensometer was attached to the test specimen at the gage section, using rubber bands, to provide a precise measurement of strain during uniaxial loading and resultant stretching of the test specimen. The stress and strain measurements, parallel to the load line, were recorded on a personal computer-based data acquisition system.

\subsection{Failure-damage analysis}

Fracture surfaces of the steel samples that were deformed and failed in uniaxial tension were carefully examined in a scanning electron microscope (SEM) to determine the macroscopic fracture mode and to concurrently characterize the fine-scale topography of the tensile fracture surface that would help establish the fine microscopic mechanisms governing failure during tensile loading. This is important to consider in light of the alloy carbides unique to this high-performance structural steel. The macroscopic mode refers to the overall mode of failure at the 'global' level, while microscopic mode considers all of the failure processes occurring at the 'local' level. Samples for observation in the SEM were obtained from the deformed and failed specimens by sectioning parallel to the fracture surface, that is, slicing perpendicular to the major stress axis.

\section{Results and discussion}

\subsection{Initial microstructure}

Optical microstructure of the chosen ASTMA572 sample is as shown in Figure 1 at two different magnifications for both the longitudinal and transverse orientations. The observed microstructure is quite

\begin{tabular}{|c|c|c|c|c|c|c|c|c|}
\hline \multirow{2}{*}{ Orientation } & \multicolumn{2}{|c|}{ Elastic modulus } & \multicolumn{2}{|c|}{ Yield strength } & \multicolumn{2}{|c|}{ Ultimate tensile strength } & \multirow{2}{*}{$\begin{array}{c}\text { Elongation: } \\
\%\end{array}$} & \multirow{2}{*}{$\begin{array}{l}\text { Reduction } \\
\text { in area: \% }\end{array}$} \\
\hline & ksi & $\mathrm{GPa}$ & ksi & $\mathrm{MPa}$ & ksi & $\mathrm{MPa}$ & & \\
\hline Longitudinal & $31 \cdot 478$ & 217 & 63 & 436 & 73 & 503 & 34 & 44 \\
\hline Transverse & $30 \cdot 483$ & 210 & 71 & 496 & 82 & 566 & 30 & 45 \\
\hline
\end{tabular}

Table 4. Ambient (room) temperature tensile properties of structural steel A572

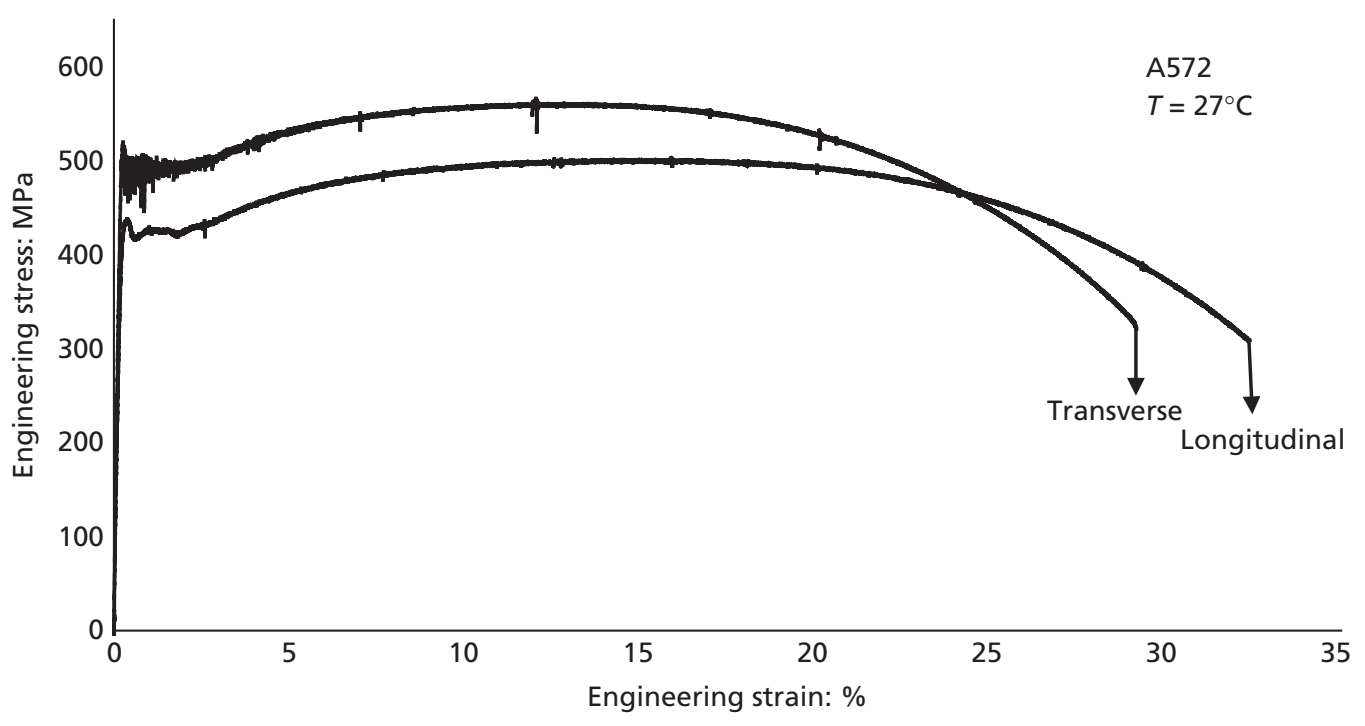

Figure 5. Influence of test specimen orientation on engineering stress against engineering strain response of structural steel A572 samples deformed in uniaxial tension at room temperature $\left(T=25^{\circ} \mathrm{C}\right)$ 
The microstructure, tensile response and fracture behavior of a high-performance structural steel: influence of orientation Gowda, Hotz, Patnaik, Manigandan and Srivatsan

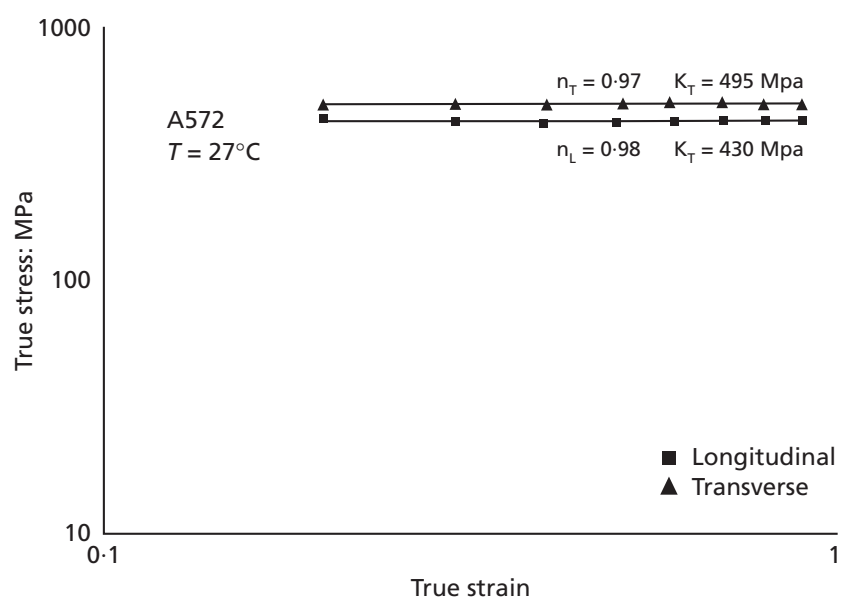

Figure 6. A comparison of the influence of test specimen orientation (longitudinal versus transverse) on true stress against true strain response of $A 572$ deformed in uniaxial tension

typical of high-carbon, low-alloy content steel. The primary microconstituent is the carbon-depleted white region referred to as ferrite. The grains are distinct and small in size and fairly nonuniform in shape. Besides this, distinguishing microconstituent dispersed through the microstructure were the second-phase particles primarily the carbides. The presence and morphology of the ferrite microconstituent are governed both by chemical composition and by the processing techniques, both primary and secondary, used to engineer this steel. These intrinsic features namely, the size and morphology of ferrite along with randomly spaced carbide particles are important factors that essentially determine its hardness, tensile properties and eventual fracture behavior at the fine microscopic level when the steel specimen is subject to uniaxial loading at the 'global' level. The two orientations (longitudinal and transverse) reveal microstructure of this alloy steel to be essentially similar with minimal difference in the nature, volume fraction, morphology, size and distribution of the intrinsic microstructural constituents.

\subsection{Hardness}

Vickers's microhardness measurements were taken edge-to-edge across the center of the polished surface of test specimens taken from both the longitudinal and transverse orientation of the highcarbon, low-alloy content steel sample. All of the measurements were made with accuracy and precision across the center of the test sample that was mounted on bakelite in order to collect information on spatial variability of hardness while minimizing contributions from location of the indent. The load used was $200 \mathrm{~g}$ for a dwell time of $10 \mathrm{~s}$. The individual microhardness values and average value are summarized in Table 3 for both the longitudinal and transverse orientations. The microhardness profile for the two orientations is shown in Figure 2. The average value of microhardness for this high-carbon, low-alloy content steel is $250 \mathrm{MPa}$ in the longitudinal orientation and $249 \mathrm{MPa}$ in the transverse orientation.

\subsubsection{Macrohardness}

The macrohardness value based on Rockwell B scale, made across the width of both the longitudinal and transverse samples, gave an average value of $432 \mathrm{MPa}$ for the longitudinal sample and $434 \mathrm{MPa}$ for the transverse sample. All measurements were made across the width of the polished surface of both the longitudinal and transverse samples. The macrohardness profile for the two orientations is shown in Figure 3. The macrohardness values for the two orientations are compared with the corresponding microhardness values in Figure 4. The bar graph representation reveals the intrinsic influence of microstructure on both microhardness, that is, 'local' hardness, and macrohardness, that is, 'global' hardness of this structural steel.

\subsection{Tensile response}

The ambient temperature tensile properties for both the longitudinal and transverse orientations for the chosen structural steel are summarized in Table 4. Results reported are the mean values based on duplicate tests.

- $\quad$ The elastic modulus in the longitudinal orientation (217 $\mathrm{GPa}$ ) of this specific steel is noticeably higher than the elastic modulus in the transverse orientation $(210 \mathrm{GPa})$.

- The yield strength in the transverse orientation (496 MPa) is $14 \%$ higher than the yield strength in the longitudinal orientation (436 MPa).

- The ultimate tensile strength in the transverse orientation $(566 \mathrm{MPa})$ is around $12 \%$ higher than that in the longitudinal orientation (503 MPa).

- The ductility quantified by elongation over $0.5 \mathrm{inch}$ $(12.5 \mathrm{~mm})$ gage length was $10 \%$ lower in the transverse orientation $(30 \%)$ than that in the longitudinal orientation (34\%). The observed lower ductility in the transverse orientation is commensurate with the higher strength in this orientation.

- $\quad$ The reduction in test specimen cross-sectional area, a measure of ductility experienced by the test specimen, was around $44 \%$.

The engineering stress against engineering strain curves for the two chosen orientations, that is, longitudinal and transverse, are compared in Figure 5. This curve clearly reveals higher yield strength and tensile strength in the transverse orientation but a noticeable decrease in ductility quantified by engineering strain or strain-to-failure $\left(\varepsilon_{\mathrm{f}}\right)$. For both the transverse and longitudinal orientations, this steel revealed observable plastic strain prior to failure by fracture.

The variation of true stress with true strain is shown in Figure 6. The true stress and true strain can be expressed in the form of a power law relationship:

2.

$$
\sigma=K\left(\varepsilon_{\mathrm{p}}\right)^{n}
$$


Emerging Materials Research

Volume 4 Issue EMR2
The microstructure, tensile response and fracture behavior of a high-performance structural steel: influence of orientation Gowda, Hotz, Patnaik, Manigandan and Srivatsan
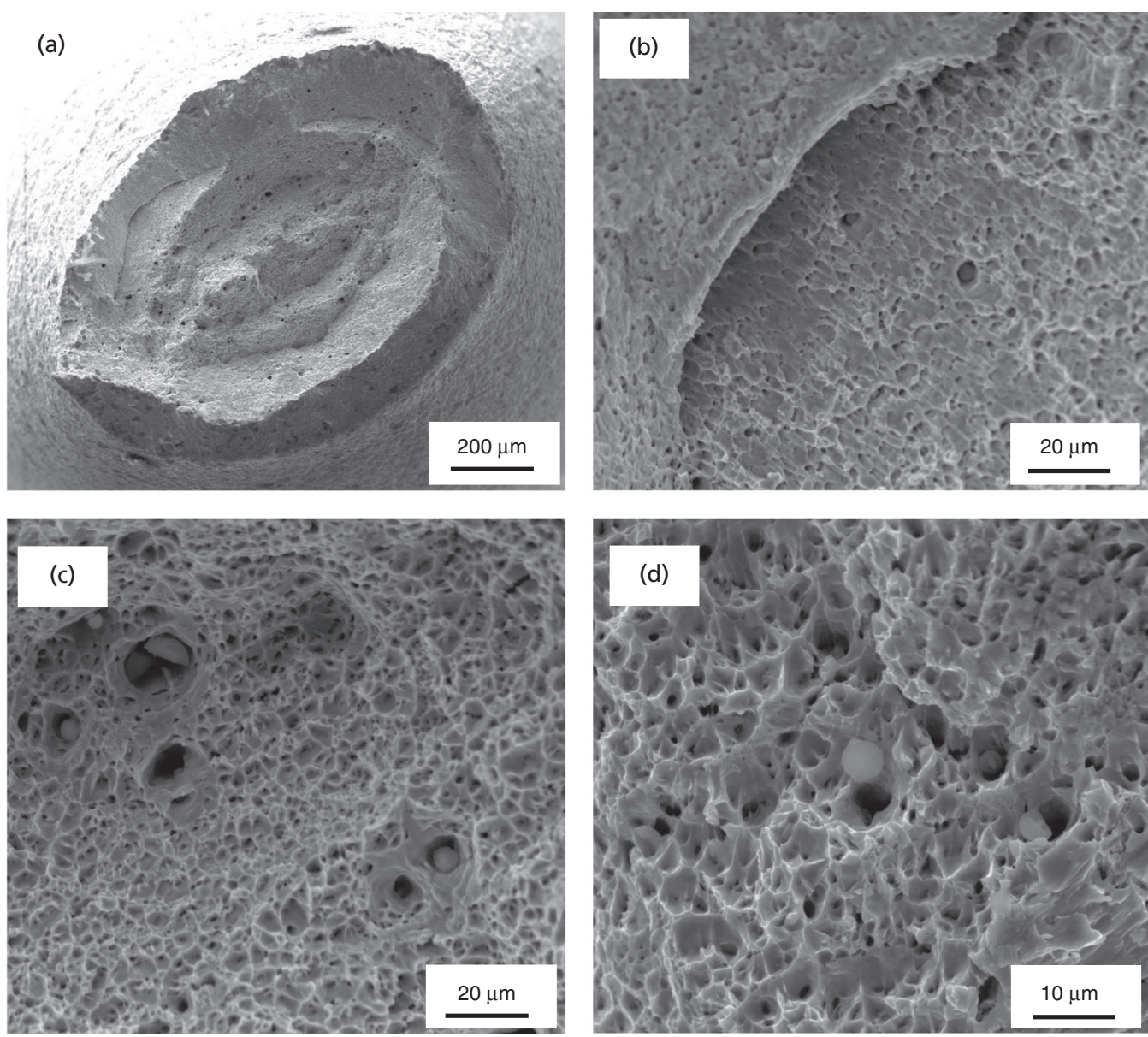

Figure 7. Scanning electron micrographs of the tensile fracture surface of the longitudinal sample of A572, showing: (a) overall morphology of failure, cup-and-cone, (b) fine microscopic voids covering the transgranular fracture region, (c) shallow dimples

The exponent ' $n$ ' provides a measure of the strain hardening capability of the chosen structural steel. This figure also reveals the chosen structural steel to have a low value of strain hardening as quantified by the strain hardening exponent $(n)$ for both the longitudinal and transverse orientations. There was minimal difference in the value of strain hardening coefficient $(K)$ for the two orientations.

\subsection{Tensile fracture behavior}

The tensile fracture surfaces of this steel for both the longitudinal and transverse orientations were carefully examined in a SEM, over a range of allowable magnifications, to provide information with specific reference to the presence and role of intrinsic microstructural effects, nature of loading and deformation characteristics of the microconstituents in governing fracture behavior of this alloy steel at the fine microscopic level. Representative fractographs for the two orientations (longitudinal and transverse) are shown in Figures 7 and 8. intermingled with voids of varying size in region immediate prior to overload and (d) ductile dimples intermingled with macroscopic and fine microscopic voids in region of overload

\subsubsection{Orientation: longitudinal}

SEM observations of the tensile fracture surface revealed fracture to be essentially cup-and-cone type (Figure 7(a)). Examination of the fracture surface at higher allowable magnifications of the SEM revealed the transgranular region to be flat, smooth and inlaid with a population of fine microscopic voids (Figure 7(b)). Gradually approaching the region of overload, the fracture surface revealed shallow dimples intermingled with both macroscopic and fine microscopic voids, features reminiscent of locally acting ductile failure mechanisms (Figure 7(c)). The region of overload revealed a healthy population of ductile dimples intermingled with both macroscopic and fine microscopic voids (Figure 7(d)). These features are clearly indicative of the dominance of 'locally' acting ductile failure mechanisms at the fine microscopic level.

\subsubsection{Orientation: transverse}

SEM observations of the deformed and failed tensile specimen revealed essentially a cup-and-cone type of failure (Figure 8(a)). 
Emerging Materials Research

Volume 4 Issue EMR2
The microstructure, tensile response and fracture behavior of a high-performance structural steel: influence of orientation Gowda, Hotz, Patnaik, Manigandan and Srivatsan (a)
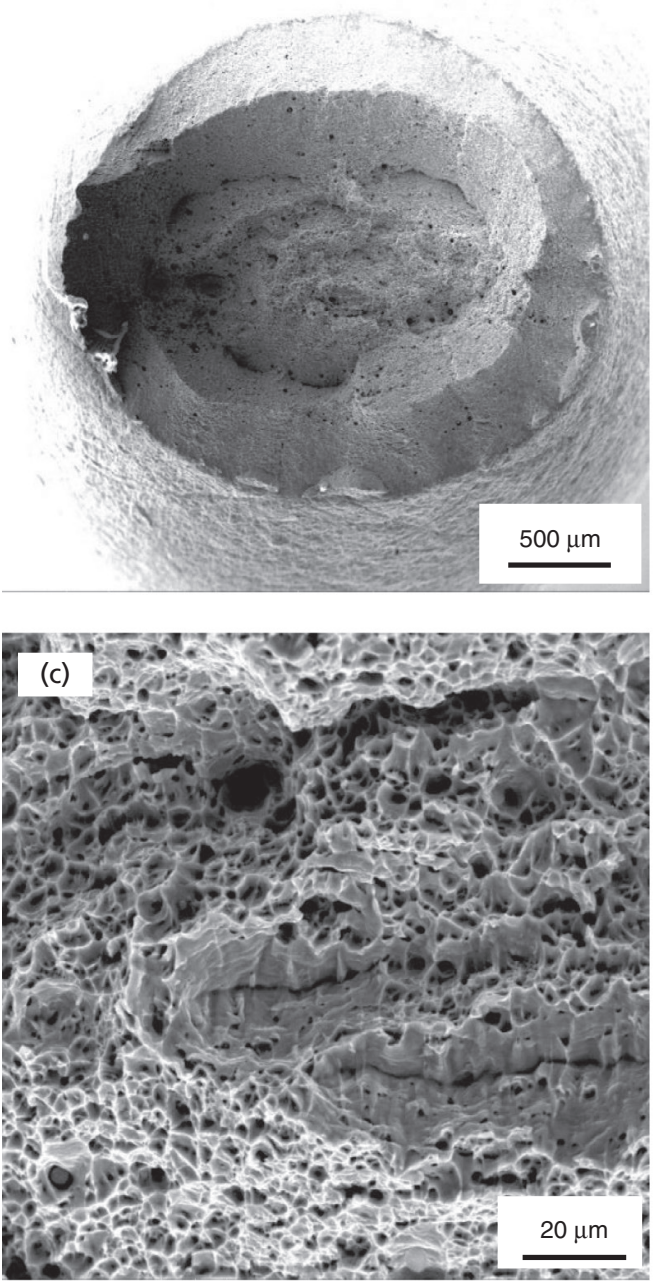

Figure 8. Scanning electron micrographs of the tensile fracture surface of the transverse sample of A572, showing: (a) overall morphology of failure: cup-and-cone, (b) transgranular region covered with voids of varying size and shallow dimples, (c) microvoid
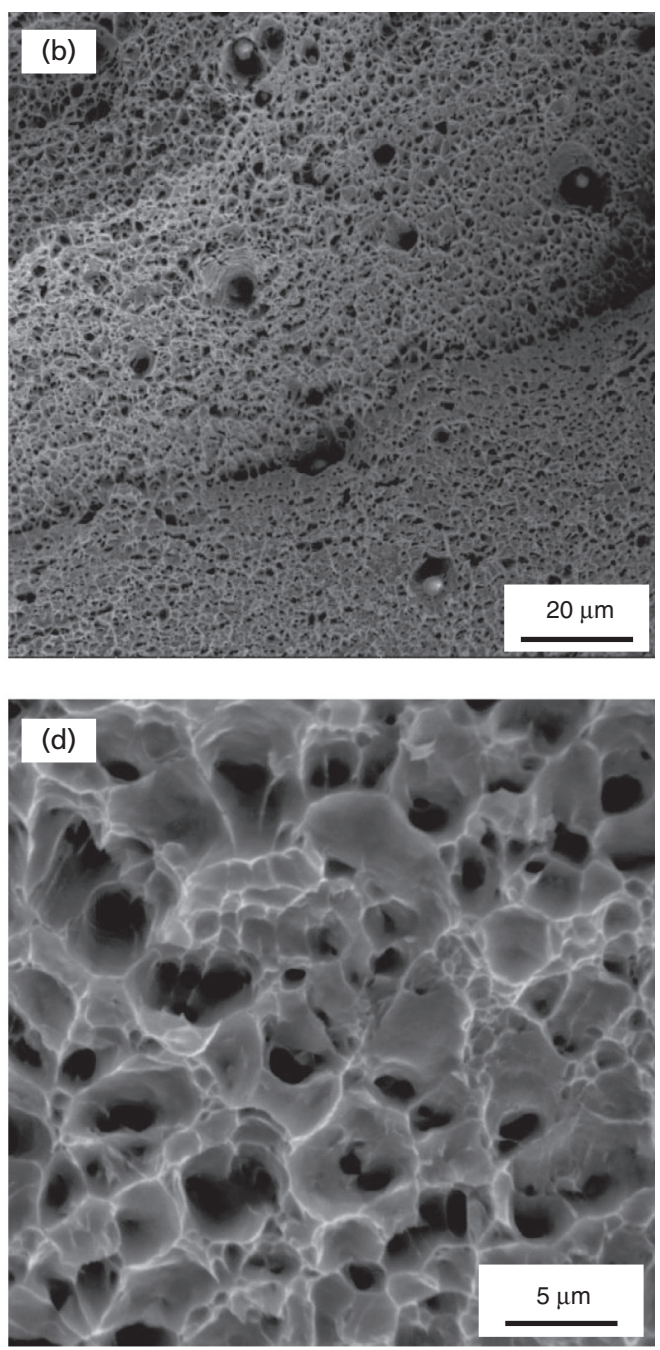

coalescence to form microscopic crack that run along the grain boundaries and (d) population of voids of varying size and shallow pockets of dimples on the overload fracture surface
Careful high magnification observations of the flat region revealed an observable population of voids of varying size intermingled with sizeable number of shallow, yet distinct, dimples (Figure 8(b)). High magnification observation of Figure 8(b) revealed the occurrence of microvoid coalescence to form microscopic cracks that traverse along the high angle grain boundaries (Figure 8(c)). The nature, morphology and distribution of both fine microscopic and macroscopic voids are distinctly seen. The region of overload revealed the presence of a healthy population of voids, of varying size and shape, and intermingled with shallow pockets of dimples. These features are clearly indicative of the occurrence of 'locally' ductile failure mechanisms prior to fracture of the test specimen (Figure 8(d)).

\subsection{Microscopic mechanisms governing stress-microstructure deformation}

\subsubsection{Interactions}

During far-field loading in tension, the gradual buildup of matrix dislocations eventually results in their pile up at grain boundaries, grain boundary triple junctions and the second-phase particles dispersed randomly through the microstructure. The gradual concentration of stress at the 'local' level favors the early initiation of fine microscopic voids at the second-phase particles dispersed through the microstructure. This is particularly favored to occur when the 'local' strain caused by the progressive buildup of dislocations at the matrix-second-phase particle interface reaches a critical value (say $\sigma^{* *}$ ). Void nucleation at the coarse second-phase 
particle is favored to occur immediately following yielding and at low values of plastic strain. During far-field loading in simple uniaxial tension, a few of the second-phase particles are favored to fracture on account of their intrinsic brittleness. This is aided by a gradual lowering of the strain energy that is required for cracking. Since crack extension under quasi-static loading is favored to occur at the high 'local' stress intensities, the presence of an observable number of both macroscopic and fine microscopic voids helps in reducing the actual strain-to-failure associated with ductile fracture.

At the fine microscopic level, the formation and presence of a noticeable number of voids of varying size transform the deforming high-carbon, low-alloy content high-strength steel into a composite material at the fine microscopic level. Since the voids are intrinsically softer than the hardened grains in the matrix, the 'local' strain is significantly elevated, both at and around the region of a microscopic void, thereby enabling a condition that facilitates in a gradual increase in their volume fraction. Half of a void is the shallow dimple that is observed in large numbers on the tensile fracture surface.

\section{Conclusions}

Based on a study of the influence of test specimen orientation on hardness, tensile properties and fracture behavior of this highcarbon, low-alloy content steel, the following are the key findings:

1. Light optical micrographs reveal a microstructure that is rich in the microconstituent ferrite, that is, the carbondepleted region. The grains are small in size and of varying shape. The second-phase particles are randomly dispersed through the microstructure.

2. The average value of microhardness for this high-carbon, low-alloy content steel is $250 \mathrm{MPa}$ in the longitudinal orientation and $249 \mathrm{MPa}$ in the transverse orientation. The macrohardness value, based on Rockwell B scale, gave an average value of $432 \mathrm{MPa}$ for the longitudinal orientation and $434 \mathrm{MPa}$ for the transverse orientation.

3. The elastic modulus of this carbon steel was higher in the transverse direction than that in the longitudinal direction. Both the yield strength and the ultimate tensile strength of this steel was higher in the transverse direction than in the longitudinal direction.

4. The ductility, quantified by elongation over $12 \cdot 5-\mathrm{mm}$ gage length, was lower in the transverse direction (30\%) than that in the longitudinal direction $(34 \%)$. The decrease is commensurate with the higher strength of steel in the transverse direction.

5. The presence of a population of voids of varying size, that is, macroscopic and fine microscopic and a noticeable population of dimples of varying size is indicative of the occurrence of ductile failure mechanisms at the fine microscopic level.
6. Both low magnification and high magnification observations of the tensile fracture surface confirm the role and/or influence of the microstructural constituents in governing the fracture behavior of this steel at both the 'global' and 'local' levels.

\section{REFERENCES}

1. Sudo, M.; Hashimoto, S.; Kambe, S. Niobium bearing ferritebainite high strength hot rolled sheet steel, with improved ductility. Transactions of the Iron and Steel Institute of Japan 1983, 23, 303-310.

2. Sudo, M.; Iwai, T. Deformation behavior and mechanical properties of ferrite-bainite-marternsite (triphase) steel. Transactions of the Iron and Steel Institute of Japan 1983, 23, 284-303.

3. Kim, I. S.; Rachel, S.; Dahl, W. Effect of bainite on mechanical properties of dual phase steels. Journal of Steel Research 1987, 58, 186-190.

4. Choi, B. Y.; Krauss, G.; Matlock, D. K. Bainite formation and deformation behavior in an intercritically annealed Fe-Mn-C steel. Scripta Metallurgica 1988, 12, 1575-1580.

5. Jeong, W. C.; Matlock, D. K.; Krauss, G. Observation of deformation and transformation behavior of retained austenite in a $0.14 \mathrm{C}-1.2 \mathrm{Si}-1.5 \mathrm{Mn}$ steel with ferrite-bainite-austenite structure. Materials Science and Engineering 1993, 165, 1-8.

6. Cingara, G. A. Effect of martensite distribution on damage behavior in DP600 dual phase steels. Materials Science and Engineering 2009, 516, 7-16.

7. Classification and designation of carbon and low alloy steels. In Metals Handbook: Properties and Selection, 10th edn. Materials Park, OH: American Society of Metals International, 1990.

8. Phillips, T. B.; McCaffrey, T. J. Ultra High Strength Steels in Metals Handbook, vol 1, 10th edn. Materials Park, OH: American Society of Metals International, 1990, 430-440.

9. Zare, A.; Ekrami, A. Influence of martensite volume fraction on tensile properties of triple phase ferrite-bainite-martensite steels. Materials Science and Engineering 2011, 530, $440-445$.

10. Liedl, U.; Traint, S.; Werner, E. A. An unexpected feature of the stress-strain diagram of a dual-phase steel. Computational Materials Science 2002, 25, 122-128.

11. Leslie, W. C. The Physical Metallurgy of Steels. New York, NY: McGraw Hill Publishers, 1981, 236-246.

12. Masahiko, F.; Yao, T.; Khedmati, M. R.; Harada, M.; Yanagihara, D. Estimation of ultimate strength of continuous stiffened panels under combined transverse thrust and lateral pressure: part 1. Marine Structures 2005, 18, 383-410.

13. Olson, G. B.; Azrin, M.; Wright, E. S. Innovations in ultrahigh strength steel technology. In Proceedings of the 34th Sagamore Army Materials Conference. Watertown, MA: U.S. Army Materials Technology Laboratory, 1990, 3-65. 
Emerging Materials Research

Volume 4 Issue EMR2
The microstructure, tensile response and fracture behavior of a high-performance structural steel: influence of orientation Gowda, Hotz, Patnaik, Manigandan and Srivatsan
14. Grondin, G. Y.; Chen, Q.; Elwi, A. E.; Cheng, J. J. Buckling of stiffened steel plates: a parametric study. Journal of Constructional Steel Research 1999, 50, 151-175.

15. AISC. Manual of Steel Construction, 13th edn. Chicago, IL: American Institute of Steel Construction, 2005.

16. Marchi, C. S.; Somerday, B. P. Low alloy ferritic steels tempered Fe-Cr-Mo alloys. In Hydrogen Compatibility of Materials. Albuquerque, NM: Sandia National Laboratories, 2000.

17. Sheikh, I. A.; Grondin, G. Y.; Elwi, A. E. Stiffened steel plates under uniaxial compression. Journal of Constructional Steel Research 2002, 58, 1061-1080.

18. Grondin, G. Y.; Chen, Q.; Elwi, A. E.; Cheng, J. J. Stiffened steel plates under compression and buckling. Journal of Constructional Steel Research 1998, 45, 125-148.
19. Birbaum, H. K. Hydrogen related failure mechanism in materials. In Symposium of the Minerals, Metals and Materials Society. Warrendale, PA: The Minerals, Metals and Materials Society, 1979, 320-360.

20. Askeland, D. R.; Phulke, P. P.; Wright, W. J. The Science and Engineering of Materials, 5th edn. USA: Thompson Publishers, 2005, 520.

21. Dieter, G. E. Mechanical Metallurgy, 3rd edn. New York: McGraw Hill Publishers, 1986, 400-420.

22. Callister, W. D. Jr. Materials in Science and Engineering: An Introduction, 6th edn. New York, London: Wiley Publishers, 2003, 134-142.

23. ASTM E8. Standard Test Method for Tension Testing of Metallic Materials. Philadelphia, PA: American Society for Testing and Materials, 2010.

\footnotetext{
WHAT DO YOU THINK?

To discuss this paper, please email up to 500 words to the managing editor at emr@icepublishing.com

Your contribution will be forwarded to the author(s) for a reply and, if considered appropriate by the editor-inchief, will be published as a discussion in a future issue of the journal.
ICE Science journals rely entirely on contributions sent in by professionals, academics and students coming from the field of materials science and engineering. Articles should be within 5000-7000 words long (short communications and opinion articles should be within 2000 words long), with adequate illustrations and references. To access our author guidelines and how to submit your paper, please refer to the journal website at www.icevirtuallibrary.com/emr

